\title{
FURTHER NOTES ON PHYLLOSOMA UTIVAEBI TOKIOKA
}

AUTHOR(S):

Tokioka, Takasi; Harada, Eiji

CITATION:

Tokioka, Takasi ...[et al]. FURTHER NOTES ON PHYLLOSOMA UTIVAEBI TOKIOKA. PUBLICATIONS OF THE SETO MARINE BIOLOGICAL LABORATORY 1963, 11(2): 425-434

\section{ISSUE DATE:}

1963-12-31

URL:

http://hdl.handle.net/2433/175331

RIGHT: 


\title{
FURTHER NOTES ON PHYLLOSOMA UTIVAEBI TOKIOKA ${ }^{12}$
}

\author{
TAKASI TOKIOKA \\ Seto Marine Biological Laboratory \\ and \\ EIJI HARADA \\ Biological Laboratory, Yoshida College \\ of Kyoto University
}

With 4 Text-figures

On the morning of May 2nd, 1963, sixteen specimens of giant phyllosomas were found stranded on the sandy beach between the north shore of the laboratory and Ezura, a small fishing village about $1 \mathrm{~km}$ east of the Laboratory, by Takasi TokiokA, Jr., who was walking there with his dog. He picked those up and brought them back to the senior author. They were completely dried up, looked like cellophane works and were very fragile. They were soaked in the warm solution of sodium phosphate, washed with fresh water carefully and preserved in alcohol for examination. Fifteen of these specimens (Stage UL), $28 \mathrm{~mm}$ to $33 \mathrm{~mm}$ in carapace length, conform quite well in every detail to the two larger specimens (Nos. 1 and 2) of Phyllosoma utivaebi described by the senior author in 1954. A pair of longitudinal crests on carapace are furnished each with 9-13 serrations, most frequently 10-11. The outer distal end of the second segment of antenna bears 4 to 7 , most frequently 5-6, teeth, besides none to six minute spinules occurring and distributing rather irregularly (Table 1 and Text-fig. 1). The marginal teeth usually diminish the size posteriorly; especially rear one to three may be very small in some specimens. Of five pereiopods, the figure and the description were given insufficiently and incorrectly only on the fourth pair in 1954. Actually, however, the appearance of the fifth segment differs conspicuously according to the order of these appendages (Text-fig. 2). There are a pair of long stout setae at the ventral side of the distal edge as the proximal portion of dactylus is embraced between these setae. The segment is armed heavily with setae; on the first pereiopod these are arranged on the ventral side of the distal half in annuli which are up to ten

1) Contributions from the Seto Marine Biological Laboratory, No. 409.

Publ. Seto Mar. Biol. Lab., XI (2), 1963. (Article 27) 
Table 1. Some measurements on fifteen specimens of Stage UL.

\begin{tabular}{|c|c|c|c|}
\hline $\begin{array}{c}\text { Specimen } \\
\text { Number }\end{array}$ & $\begin{array}{c}\text { Carapace } \\
\text { length }\end{array}$ & $\begin{array}{c}\text { Number of serrations } \\
\text { on longitudinal crests }\end{array}$ & $\begin{array}{c}\text { Number of teeth at the outer } \\
\text { distal end of the second seg- } \\
\text { ment of antenna }\end{array}$ \\
\hline 1 & $28 \mathrm{~mm}$ & $9-10$ & $6-6$ \\
2 & 29 & $12-13$ & $5+(1) *-6$ \\
3 & 29 & $10-10$ & $4-5$ \\
4 & 30 & $11-11$ & $6+(3)-7+(3)$ \\
5 & 30 & $11-11$ & $5-5$ \\
6 & 30 & $11-11$ & $5-5+(3)$ \\
7 & 30 & $10-12$ & $6-7$ \\
8 & 30 & $10-11$ & $7+(4)-6+(6)$ \\
9 & 31 & $10-10$ & $6+(3)-5+(2)$ \\
10 & 31 & $10-11$ & $5+(2)-?$ \\
11 & 31 & $10-11$ & $5-7$ \\
12 & 31 & $11-13$ & $4+(3)-5+(3)$ \\
13 & 31 & $10-11$ & $5+(4)-5$ \\
15 & 32 & $11-11$ & $4+(5)-5+(5)$ \\
\hline
\end{tabular}

* Numerals in parentheses indicate numbers of spinules.

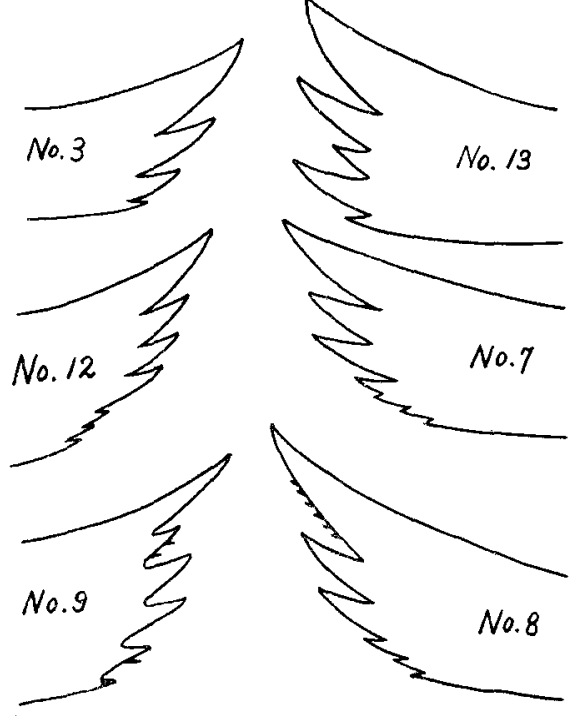

Text-fig. 1. Variation found in the denticulation at the outer distal end of the second segment of antenna. Numerals show specimen numbers. 
in number and become obscure proximally. This annular arrangement becomes less remarkable on the second, it is hardly discernible on the third and on the fourth, and on the fifth leg it disappears completely. Dactylus has several spinules in addition to a prominent spine at the middle of the dorsal margin on the first and the second leg, only a few spinules on the third, but none on the fourth and the fifth (Text-fig. 2). The appearance and distribution of gill in fifteen specimens conform exactly to those described in 1954 on the two specimens (Nos. 1 and 2) (Table 2).

Table 2. Distribution of gills on appendages in Stage UL.

\begin{tabular}{|l|c|c|c|}
\hline Appendages & Pleurobranchia & Arthrobranchia & Podobranchia \\
\hline 2nd Maxilliped & - & 1 & 1 (bifid) \\
3rd Maxilliped & 1 & 1 & $1(")$ \\
1 Pereiopod & 1 & 1 & $1(")$ \\
2 Pereiopod & 2 & 1 & $1(")$ \\
3 Pereiopod & 2 & 1 & $1(")$ \\
4 Pereiopod & 2 & 1 & $1(")$ \\
5 Pereiopod & 1 & - & - \\
\hline
\end{tabular}

Another specimen (Stage UL-2) is much smaller than others. The carapace is only $21 \mathrm{~mm}$ long and $25 \mathrm{~mm}$ wide. Serranations on the longitudinal crests are 8-9. The appearance of abdominal segments resembles closely that of the preceding specimens, although the fine denticulation is quite missing along the posterior margin of respective segments and the lateral spines of the telson are comparatively much more prominent (Text-fig. 4-N). The distal segment of antenna is rather elongate (Text-fig. 4-M). The outer distal end of the second segment of antenna bears four teeth on each appendage and the basal segment bears a small spine at each of inner and outer distal edges. The structure of the mouth parts resembles roughly that in Stage UL, but shows slight differences in some aspects. The blade edge of mandible (Text-fig. 4-O) has about twenty bristles. Its anterior angle is projected out into an elongate prominence bearing a few minute teeth on the dorsal side (Text-fig. 4-P \& Q). The posterior angle is strongly curved dorsally and forms a papillated oval area. An inconspicuous thickening is found near the middle of the anterior edge. The outer ramus of maxillula has no seta at the middle of its outer margin (Text-fig. 4-T). The distal prominences of the first maxilliped are nearly of the same length (Textfig. 4-S). Dactylus of the second maxilliped is much more slender than in Stage UL, the exopodite is still in a state of small elongate prominence (Textfig. 3-K). The' structure of pereiopods resembles that in Stage UL (Text-fig. 3-F to $\mathrm{J}$ and Table 3 ). Pleopods do not yet show any articulations, the exopodite is shorter than the endopodite which bears no appendage on the inner margin 


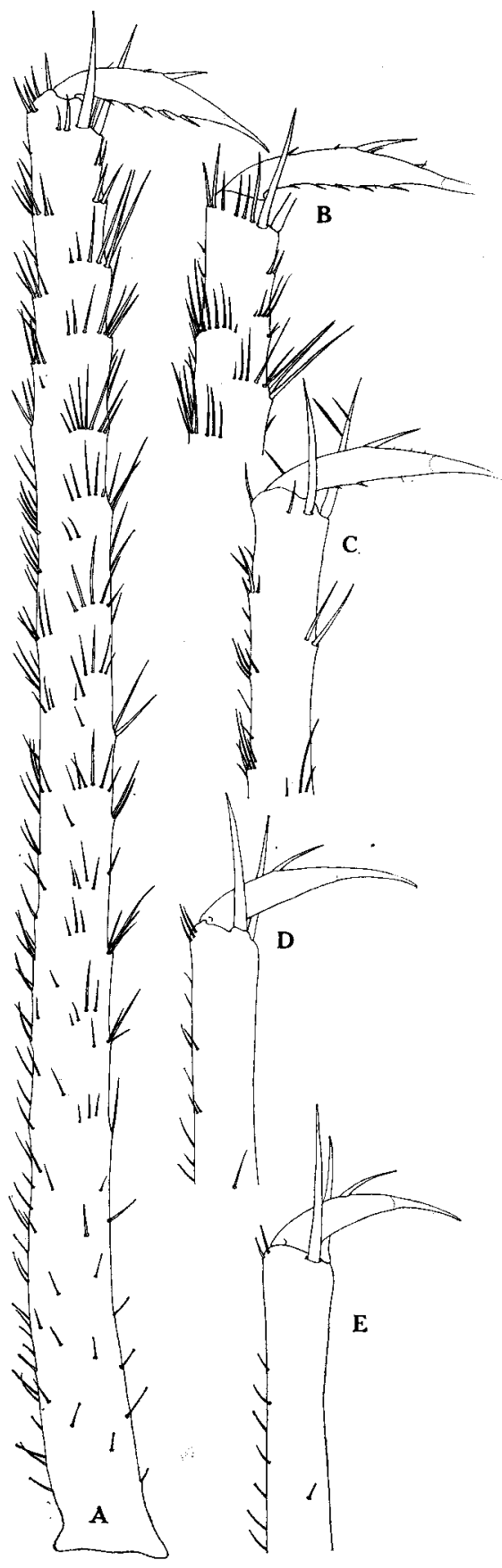

Text-fig. 2. Arrangement of setae on dactylus and the 5th segment in pereiopods (Stage UL). A-the first, B-the second, $\mathrm{C}$-the third, $\mathrm{D}$-the fourth, and $\mathrm{E}-$ the fifth pereiopod, $\times 9.3$. 


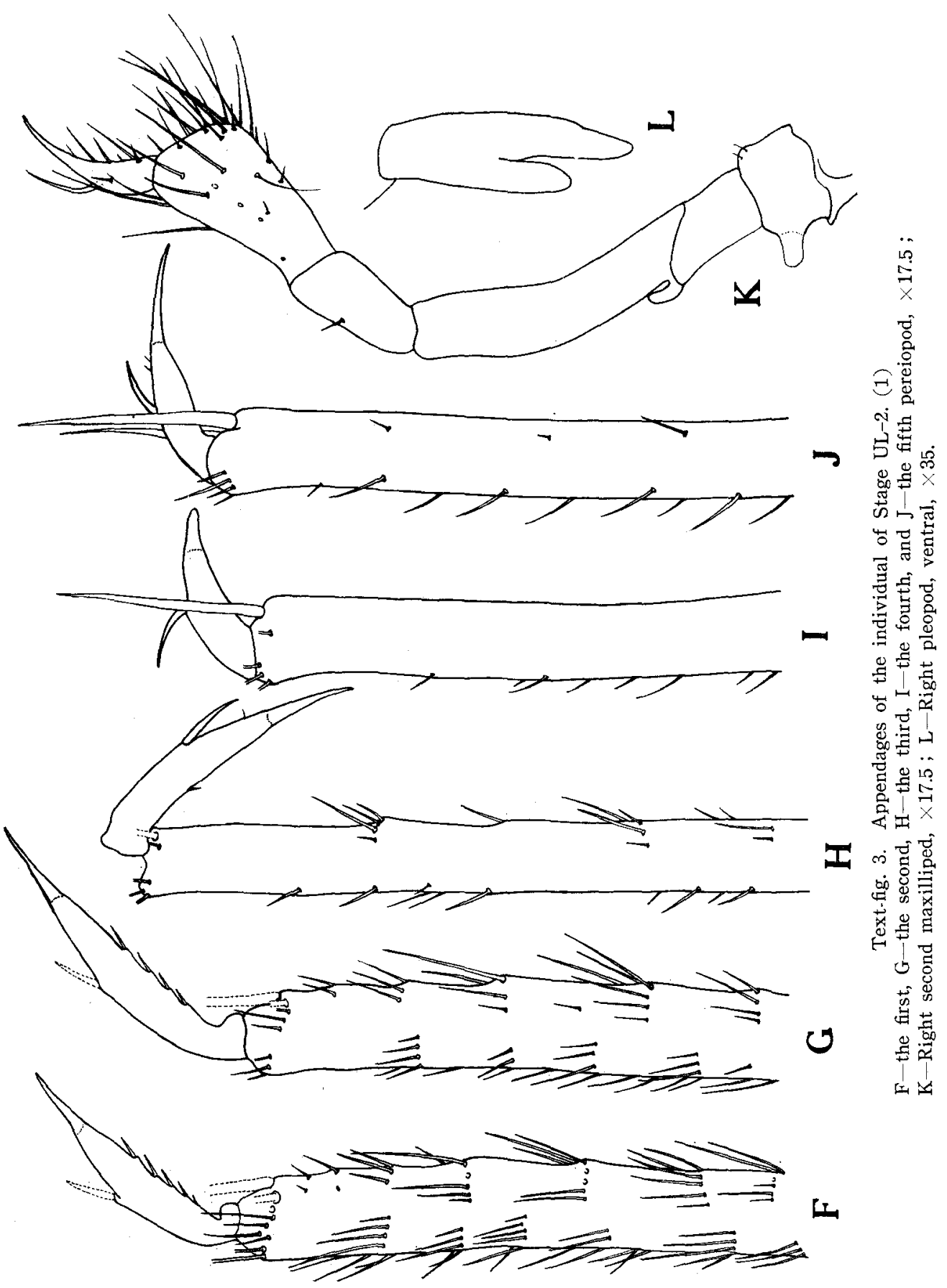




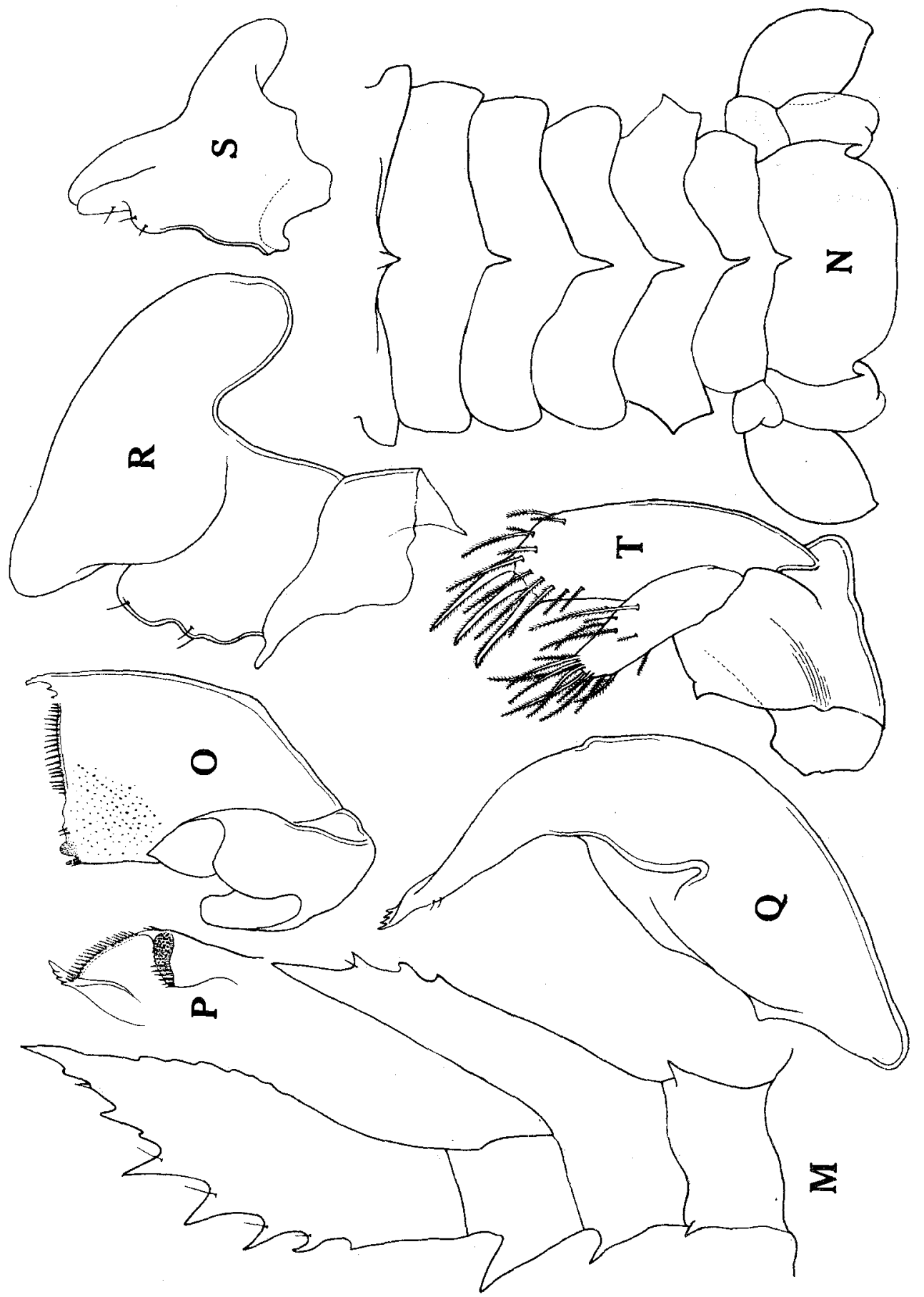

苍苛

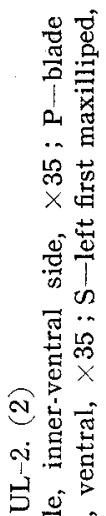

品视

岕芯

责市

害倣

$\exists \bar{x}$

㟧焉

总范

है

塎

bi 苑

离壳的 世z 난 
Table 3. Length of respective segments of pereiopods (Stage UL-2).

\begin{tabular}{|c|l|l|l|l|l|l|l|}
\hline $\begin{array}{c}\text { No. of } \\
\text { Pereiopod }\end{array}$ & $\begin{array}{c}\text { Length of } \\
\text { Coxa }\end{array}$ & Basis & $\begin{array}{l}\text { 3rd } \\
\text { Seg. }\end{array}$ & $\begin{array}{l}\text { 4th } \\
\text { Seg. }\end{array}$ & $\begin{array}{l}\text { Sth } \\
\text { Seg. }\end{array}$ & Dactylus & Exopodite \\
\hline 1 & $2 \mathrm{~mm}$ & $7.5 \mathrm{~mm}$ & $6.5 \mathrm{~mm}$ & $5 \mathrm{~mm}$ & $12.5 \mathrm{~mm}$ & $1.5 \mathrm{~mm}$ & $19 \mathrm{~mm}$ \\
2 & 2 & 6 & 7 & 5 & 15 & 2 & 21 \\
3 & 2 & 5.5 & 7.5 & 5 & 14 & 2 & 19 \\
4 & 2 & 5 & 7 & 4 & 11.5 & 1.5 & 17 \\
5 & 2 & 4 & 6 & 3 & 8 & 1.5 & 13 \\
\hline
\end{tabular}

Table 4. Distribution of gills on appendages in Stage UL-2.

\begin{tabular}{|l|c|c|c|}
\hline \multicolumn{1}{|c|}{ Appendages } & Pleurobranchia & Arthrobranchia & Podobranchia \\
\hline 2nd Maxilliped & - & - & bud \\
3rd Maxilliped & - & - & bud \\
1 Pereiopod & - & - & bud \\
2 Pereiopod & - & - & bud \\
3 Pereiopod & - & - & bud \\
4 Pereiopod & - & - & bud \\
5 Pereiopod & - & - & - \\
\hline
\end{tabular}

(Text-fig. 3-L). Gills are all still in a stage of bud, a small prominence (Table 4).

The fifteen specimens and the spectmens Nos. 1 and 2 described in 1954 seem to represent the ultimate stage of the pelagic life for this species, as the specimens of this type occur frequently and most abundantly and yet none of any more advanced stages has ever been found; thus this is defined as Stage UL. The differences between the specimens of this stage and the smaller one described here are so distinct that the latter represent evidently a younger stage than UL. While, the differences between the individuals of Stage UL and the specimen No. 3 described in 1954 are rather slight; the latter might be nothing but a malformed individual of Stage UL (Table 5). As there is only a single specimen of this type, it is impossible to make certain whether this represets a distinct stage or not.

Table 5. Distribution of gills on appendages in Stage UL-1.

\begin{tabular}{|l|c|c|c|}
\hline \multicolumn{1}{|c|}{ Appendages } & Pleurobranchia & Arthrobranchia & Podobranchia \\
\hline 2nd Maxilliped & - & - & 1 (simple or bifid) \\
3rd Maxilliped & 1 & 1 & 1 (bifid) \\
1 Pereiopod & 1 & 1 & $1(")$ \\
2 Pereiopod & 2 & 1 & $1(")$ \\
3 Pereiopod & 2 & 1 & $1(")$ \\
4 Pereiopod & 2 & 1 & $1(\eta)$ \\
5 Pereiopod & 1 & - & - \\
\hline
\end{tabular}


However, it is requested to give some sign to this type to describe and record the actual facts. Then, for the convenience of recording, this type is treated as representing an intermediate stage between UL and the smaller specimen described here and therefore is named UL-1; the present smaller specimen is then indicated as UL-2.

As a matter of fact, the larval stages of Ibacus have not yet been fully accounted for, even morphologically. The first description of the larvae occurring in the Japanese waters was made as early as in 1850 by DE HAAN, though that and the following works were mostly on the larger larvae of later stages and very seldom for earlier stages. It should be regarded natural and inevitable, for, as in the present case, the larger larvae ascribable with certainty to the genus have beed collected so often and in number, whereas, strange enough, a few smaller larvae have been sorted out from various collections and are difficult to be identified. The description of the first stage phyllosoma of Ibacus ciliatus by the junior author-as will be mentioned elsewhere, there has been arisen some doubt of the identification of the species-afforded a clue for field collection of earlier larvae, and Saisho and NAKAHARA (1960) succeeded to rear and gave the following three phyllosoma stages. Shojima (1963) discussed on the field collections of large phyllosoma larvae of Ibacus ciliatus and Scyllarus, in which he described a rather curious habit of them to cling on to jelly-fishes.

There has been no record succeeding to rear up and to get the young or adult animal of Ibacus from eggs, and we do not know how the whole larval life is passed and how long it takes. However, judging from the fragmental knowledges hitherto obtained, spawning takes place from April to early summer (Harada, 1958; Saisho and Nakahara, 1960), the phyllosoma larvae emerged from eggs moult successively in planktonic life. Larger phyllosoma larvae, as dealt in the present paper, which are occurring in the coastal water or in the plankton, also appear and have been caught mostly during May to July (TokiokA, 1954 ; Shojima, 1963), but they are hardly supposed to be the immediate population growing from the batch of those spawned in the same year, since it has been recorded that the first stage phyllosoma larvae take nearly a month to grow up into the fourth phyllosoma stage.

As in the case of the common Japanese spiny lobster, Panulirus japonicus, for which more than ten phyllosoma stages have been made clear by SAIsHo (1962) and Inoue and NonaKa (1963), still most of the larval life have not been known well. It view of stepping forward in the study of this line, it might be of importance to trace back the larval life from the larger stages in the field collection which are occurring more often, as well as to rear the first phyllosoma larvae up, particularly for these species of long larval life. The reason why the ultimate stage phyllosoma larvae are caught so often is not clear and remains to be clarified. 
The best criterion or character to stage the larvae appears to be the gill structure and their arrangement. Although serrations, spines and spinules, and setae are varying according to the stage, they also show wide variations among individuals of the same stage. The difference in appearance and distribution of gills is, in contrast, so well marked as described earlier, and is also remarkable between those and that of following natant or young stage.

Recently, another species of the genus, Ibacus peronii H. Milne-EdWARds, recognized to be occurring quite abundantly in the Japanese waters by Prof. Kuвo and the junior author, this will be discussed elsewhere by the junior author. The major difference between these two species of Ibacus appears on the third maxilliped. It is however rather difficult to correlate the morphology of maxillipeds of the present larvae with that of the adult of either species and is needed further observations.

Some of the larvae of Stage UL collected were found carrying rather large colonies of the hydroid, Obelia geniculata (Linnaeus)*, and infant Lepas. This could be regarded as a proof that the stage concerned is long enough to allow these animals to grow. Much more detailed studies on the larvae on this line might be helpful to elucidate their natural life.

\section{REFERENCES}

HAAN, W. DE, 1833 50. Crustacea. In : P. F. DE SIEBold's Fauna Japonica, pp. 1-244, Pls. 1-55, A-Q.

HARADA, E. 1958. Notes on the naupliosoma and newly hatched phyllosoma of Ibacus ciliatus (VON Siebold). Publ. Seto Mar. Biol. Lab., Vol. 7, No. 1, pp. 173-180, Pls. IX-XI.

Inoue, M. and Nonaka, M. 1963. Notes on the cultured larvae of the Japanese spiny lobster, Panulirus japonicus (v. Siebold). Bull. Jap. Soc. Sci. Fish., Vol. 29, No. 3, pp. 211-218.

SaIsHo, T. 1962. Notes on the early development of phyllosoma of Panulirus japonicus. Mem. Fac. Fish. Kagoshima Univ., Vol. 11, No. 1, pp. 18 23. (in Japanese)

SAISHO, T, and NAKAHARA, K. 1960. On the early development of phyllosomas of Ibacus ciliatus (von Siebold) and Panulirus longipes (A. Milne Edwards). Ibid., Vol. 9, pp. 84-90.

ShojImA, Y. 1963. Scyllarid phyllosomas' habit of accompanying the jelly-fish (Preliminary report). Bull. Jap. Soc. Sci, Fish., Vol. 29, No. 4, pp, 349-353.

TokIOKA, T. 1954. Droplets from the plankton net. XIV. Record of a scyllarid Phyllosoma near Seto. Publ. Seto Mar. Biol. Lab., Vol., 3, No. 3, pp. 361-368, Pls. 41-43.

* We are very grateful to the authorities of the Biological Laboratory, Imperial Household, for this identification. 
Postscript:-Two more phyllosomas referable to the present form were examined after the manuscript was submitted to the printer.

One is a specimen of Stage UL with a carapace $32 \mathrm{~mm}$ long and $37 \mathrm{~mm}$ wide and having 10-11 serrations along each of the carapace ridges. The outer distal end of the second segment of antenna bears respectively $4-5$ teeth and 2-3 posterior spinules; there are 4-6 moderate to small prominences along the anterior margin of the segment. The posterior ramus of podobranchia is considerably shorter than the anterior one. The specimen was collected along the northern coast of Wakayama prefecture (Arita-gun) in the summer season (?) and kept by Dr. I. YamazI.

The other specimen, with a carapace $31 \mathrm{~mm}$ long and $35 \mathrm{~mm}$ wide and having 10-11 serrations along respective carapace ridges, was found by $\mathrm{Mr}$. Yosida on November 10, 1957 at Yura Port (Arita-gun) and presented to the senior author by his brother Commander Takami TokiokA. The outer distal end of the second segment of antenna bears each 4 teeth and 2 posterior spinules; there are 1-2 spinules along the anterior margin. The short exopodite of the 3rd maxilliped seems to be faintly articulated near the middle, and there is an indistinct articulation in a short distance to the proximal end of the 3rd segment of the same maxilliped. Gills show the typical distribution for Stage UL on the right body half, while on the left the second maxilliped lacks the arthrobranchia and the podobranchia is still uniramous. This might be a malformation found in Stage UL or Stage UL-1, though the former is more possible as the specimen is large enough. Some of the serrations along the carapace ridges are coloured dark brown at the tip. It is noteworthy that the specimen was caught while the collector was joking in hooking up jelly-fishes in daytime, as SHôjima (1963) shows a supposed relation between phyllosomas and medusae. 